\title{
Experiences of Students with Visual Impairment in Higher Education in Ghana: Bodily Perspective on Inclusive Education
}

\author{
Ivy Ama Kpodoe \\ University of Cape Coast Department of Psychology and Education \\ *Joseph Ampratwum \\ KNUST Centre for Disability and Rehabilitation \\ Afua Ntoaduro \\ Wesley College of Education Department of Education \\ Florence Yeboah \\ Mampong Technical College of Education Department of Education
}

\begin{abstract}
The study examined experiences of students with visual impairment in Ghana's public universities. The study employed the cross-sectional descriptive survey design using semi-structured questionnaire for data collection to provide answers to the research questions. The study population included all students with visual impairment across the three Public Universities namely; University of Ghana, University of Cape, and University of Education, Winneba. In all, 87 students with visual impairment were purposively selected to participate in the study. The study revealed that students with visual impairment in these three public universities experience several attitudinal challenges both from teachers, resource persons and fellow students which affect their academic achievement. Also, students with visual impairments in Ghana's public universities are constantly challenged by classroom instructional strategies, and that it is difficult for them to access course outlines, textbooks, among other relevant facilities in advance. It is recommended that the Special Education Division of the Ministry of Education in conjunction with the Resource Persons in the various universities should organize periodic in-service training programmes for university teachers who teach in the inclusive public universities to adequately equip them in handling the visually impaired.
\end{abstract}

Keywords: visual impairment, inclusive education, resource person, disabilities and Ghana

DOI: $10.7176 / \mathrm{JEP} / 10-18-17$

Publication date: June $30^{\text {th }} 2019$

\section{Introduction}

Education is a principal instrument for preparing children and the adult for a better life and national development. It is doubtful to expect that any child, let alone the visually impaired, can be successful in life if he or she is denied access to quality education. Persons with disabilities' denial of access to quality education come as a result of the perception society have which influences their attitudes towards them (Dyson \& Gallannaugh, 2007). As a result of such attitude, many children, youth and adults with disabilities are denied of their basic rights despite the existence of international rules and national laws advocating for the equalisation of opportunities for persons with disabilities.In recent years, there has been a growing international urgency to include visually impaired in university campuses. Ideally, this inclusion runs deeper than a mere increase of visually impaired students on tertiary grounds; it also involves the quality of the social and academic challenges of students with visual impairment once they have gained access to higher education (Fuller, 2004). In essence, inclusion of visually impaired means feeling like a welcomed member of the tertiary environment; a member that truly belongs and whose contributions to the diversity of the university are valued and celebrated (Swart and Greyling, 2012). What has been missing from previous research on visually impaired students is an embodied account of their social and academic challenges. So far we have heard their accounts of the learning and social environment, but we have not heard how they experience the tertiary environment with their flesh and bones. It is partly, and crucially, through the lens of their lived realities that the ability of universities to implement inclusive policies will be illuminated (Brandt, 2011). What is more, an account, where bodily experiences of social and academic challenges of visually impaired are recognized and documented, may point us in the direction that is needed for change. The need for inclusive education in order to ensure that disabled persons are included in the educational provision has become imperative to guarantee access to equal educational opportunities. 'Communication socializes people and makes them express their feelings and thoughts' (Gadagbui, 2006: 275). Negative and harmful attitudes towards difference in our society remain critical barriers to learning and development. Discriminatory attitudes resulting from prejudice against people on the basis of race, class, gender, culture, disability, religion, ability, sexual preference and other characteristics manifest themselves as barriers to learning when such 
attitudes are directed towards learners in the education system. Article 26 of the United Nations Charter on Education (1974) (as cited in Johannes, 1999) re-echoed at the United Nations Convention on the Rights of Persons with Disabilities stated that everyone has the right to education. Education shall be free, at least in the elementary and fundamental stages. Elementary education shall be compulsory. Technical and professional education shall be made generally available and higher education shall be equally accessible to all on the basis of merit. In Ghana, despite the advancement in tertiary education for students with disabilities, it appears tertiary institutions have not been originally structured to accommodate students with visual impairment. It is uncertain whether lecturers and regular students have the expertise in coping with the students. Whether students are guided and counselled by the counselling units of the universities when they gain admission, the type and quality of support services rendered by resource persons and whether government policies on inclusive education are fully implemented are questions that remain unanswered. Much as it is important to include persons with visual impairment in the university education, it should be borne in mind that without lecturer and peer preparation to accept them, very little can be achieved. It is observed that in Ghana, many problems are being encountered as far as inclusive education programmes are concerned (Mensah, 2000). Avoke and Hayford (2002) reported that only a few of their teacher participants had knowledge of SEN methodology and principles. People's attitude toward the visually impaired in the universities can influence their academic achievement. Harris, FinkChorzempa and Mac-Arthur (2003) upheld that attitudes have a major impact on behaviour and one's ability to manage and adapt to change. Teachers' attitudes are known to influence their teaching practices and management strategies and therefore directly influence students' learning (Gyimah, 2006). The problem statement of this study is also linked to the issue that, despite the fact that some works have been done regarding the mainstreaming of students with visual impairment, the impacts of attitudinal challenges on the academic achievements of students with visual impairments at the university level in Ghana is yet to be systematically verified by empirical evidence (Ocloo, 2000). It is in this light that the researchers sought to empirically find out the peculiar attitudinal challenges to academic achievement of students with visual impairment in the public universities in Ghana.

\section{Objectives}

1. Examine the social challenges of students with visual impairment in the public universities in Ghana

2. Assess how students with visual impairment are accommodated in the public universities in Ghana.

3. Identify the support services available for students with visual impairment in the public universities in Ghana.

\section{Research questions}

1. What are the social challenges of students with visual impairment in Ghana's Public Universities in Ghana?

2. How are students with visual impairment accommodated in the Public universities in Ghana?

3. What are the support services available for students with visual impairment in the public universities in Ghana?

\section{Materials and methods Study design and type}

This cross-sectional descriptive survey study adopted quantitative method of data collection, using semi structured questionnaire to elicit information from participants. Semi structured questionnaire helped the researchers gather wide range of information from a large number of respondents. The questionnaire allowed the researchers to get close to the data thereby developing analytical, conceptual and categorical responses from the participants. The quantitative method also allowed adaptation to changing conditions and/or new insights into all aspects of the situation under investigation (Creswell, 2008).

\section{Study population and sampling}

The target populations for the study consisted of all the three public universities educating students with visual impairments in Ghana. Purposive sampling technique was used to select participants for the study. Students with visual impairment were obtained from the resource centres of the participating universities. These were 23 students from university of Ghana, 37 students from university of Cape Coast and 27 students from university of education.

\section{Procedure for data collection}

The researchers obtained a letter of introduction explaining the purpose of the research to the registrar's office of the three public universities in Ghana. The purpose of the letter was to seek approval from the registrar's Office for this study. A questionnaires was developed and administered to students independently after the purpose of the study has been explained to them. The questionnaire covered the following areas: social experiences of 
students with visual impairment, accommodation of students with visual impairment in the universities, support services available for students with visual impairment in the public universities and perception about the policy

\section{Ethical consideration}

Ethical codes approved by the Kwame Nkrumah University of Science and Technology for conducting research with human subjects were followed throughout the fieldwork, Ethical clearance was obtained from the University's research committee as well as the three public universities in Ghana practicing inclusive education. Efforts were also made to protect the confidentially and anonymity of participants and to ensure that they were not exposed to any risk during the study. Each participant was asked to sign an informed consent form, which described the purpose of the study, the risks, benefits, and the voluntary nature of their participation before they were given the questionnaire.

\section{Data analysis}

Prior to data entry, data from the field was processed. Thus, a manual review of all completed questionnaires was done to make sure that every stated question was asked, while reviewing all responses for accuracy, clarity, and logic with special attention to the recoding of open-ended questions. Instances where it was not possible to correct these problems prior to the data analysis phase, statistical procedures such as frequencies were used for data validation.

Quantitative data was analysed using the Statistical Package for the Social Sciences (SPSS) Version 22, now called the Statistical Product and Service Solutions (SPSS). Descriptive statistics and cross-tabulations were calculated using the chi-square test of independence to determine significant differences among variables. Inferential analysis was also done using the Regression analysis and the Analysis of Variance. Regression analysis was done to determine the contribution of attitudinal challenges in predicting academic achievements of the visually impaired. The criterion variable was therefore regressed on the explanatory variables. Analysis of Variance on the other hand was used to determine if there is any mean difference in attitudinal challenges of students across the three participating universities.

\section{FINDINGS}

\section{Social Challenges of Students with Visual Impairment in the Inclusive Public Universities}

In exploring the social challenges, the study classified the challenges based on guidance from colleagues, academics; with regards to going for lectures, transportation within campus, and participation in recreational activities.

\section{Guidance from Colleagues}

Findings revealed that more than half $(55.2 \%)$ of the students with visual impairment agreed that their sighted colleagues do not always guide them willingly. Table 7 depicts the results

Table 1: My Sighted Colleagues do not Always Guide me willingly

\begin{tabular}{lll}
\hline Response & Frequency & Percent \\
\hline Strongly agree & 18 & 20.7 \\
Agree & 30 & 34.5 \\
Disagree & 29 & 33.3 \\
Strongly disagree & 10 & 11.5 \\
\hline Total & $\mathbf{8 7}$ & $\mathbf{1 0 0}$ \\
\hline
\end{tabular}

Source: Survey data, 2012.

This implies that, the proportion of respondents who agreed was10.4 percent higher than the proportion of respondents who disagreed. Also, 50.1 percent of the respondents showed that their fellow colleagues did not approach them to help when they found their way out to places other than lectures.

Further analysis using the independent t-test showed that respondents getting their sighted colleague to assist them did not differ across gender $\left(\chi^{2}=5.749, p=0.113\right)$. In other words, both male and female students with visual impairment did not always get support from their colleagues. This implied that most sighted colleagues did not always guide the visually impaired willingly. Why the resentment on the part of the sighted colleagues? Could it not be due to their misunderstanding and negative social attitude? Could it not also be probable they think it is a curse to be visually impaired? It could also be explained on the basis of the delays the conditions of the visually impaired cause. This corroborates with the finding of Tibebu (cited in Avramidis, Bayliss and Burden (2000) that students with impairments were not accepted by their 'normal' counterparts for varied reasons. Almost 90 percent $(89 \%)$ of the respondents indicated that it is not all students who tolerate the delays their condition causes them.

In relation to respondents' colleagues approaching them to help when they find their way out to places other than lectures, 50.1 percent of the respondents showed that their fellow colleagues did not approach them when 
they found their way out to places other than lectures. The results are shown in Table 8 .

Table 2: Colleagues do not Approach me to help when I find my Way out to Places other than Lectures

\begin{tabular}{lll}
\hline Response & Frequency & Percent \\
\hline Strongly agree & 16 & 18.4 \\
Agree & 19 & 21.8 \\
Disagree & 44 & 50.6 \\
Strongly disagree & 8 & 9.2 \\
\hline Total & $\mathbf{8 7}$ & $\mathbf{1 0 0}$ \\
\hline
\end{tabular}

Source: Survey data, 2012.

Further, Analysis of Variance was performed to determine any mean difference in the help students with visual impairment obtained from their sighted colleagues across the three participating universities. Table 9 shows the result.

Table 3: My Sighted Colleagues do not Always Guide me willingly

\begin{tabular}{|c|c|c|c|c|c|}
\hline & Sum of squares & $\mathrm{df}$ & Mean Square & $\mathrm{F}$ & Sig \\
\hline Between Groups & 11.039 & 2 & 5.520 & 7.337 & 0.001 \\
\hline
\end{tabular}

Source; Survey data, 2012

The ANOVA results in Table 9 showed that there were significant $(\mathrm{p} \leq 0.005)$ mean difference in obtaining genuine help by visually impaired across the three universities from their sighted colleagues. Since there were statistical significant mean differences across the three universities, a further post-hoc test was performed using the Least Significant Difference to determine the University with the highest contribution into the difference. University of Ghana was noted as the University where students with visual impairment do not always receive help from their sighted colleague. There were however, no differences in the mean help from sighted colleagues across the University of Cape Coast and the University of Education. Table 4 shows the views of respondents in feeling secured while in the midst of sighted colleagues. With regards to social security among sighted colleagues, more than half $(66.7 \%)$ of the respondents showed they do not feel fully secured when in the midst of sighted colleagues. That is to say only 33.3 percent thought of being secured in the midst of their sighted colleagues.

Table 4: I Feel Secured Being in the Midst of Sighted Colleagues

\begin{tabular}{lll}
\hline Responses & Frequency & Percent \\
\hline Strongly agree & 12 & 13.8 \\
Agree & 17 & 19.5 \\
Disagree & 38 & 43.7 \\
Strongly disagree & 20 & 23.0 \\
\hline Total & $\mathbf{8 7}$ & $\mathbf{1 0 0}$ \\
\hline
\end{tabular}

Source: Survey data, 2012

In Table 11 , a greater proportion $(65 \%)$ of the male respondents disagreed that they do not feel secured when they are in the midst of their sighted colleagues. Similar responses were noted for the female population where half $(70 \%)$ also disagreed that they do not feel secured.

Further analysis shows that there were however, no significant differences $\left(\chi^{2}=2.240, p=0.524\right)$ in feeling secured in the midst of sighted colleagues across respondents gender. This implied that the unsecured feeling among respondents when in the midst of their sighted colleagues was highly independent on their gender, and that both male and female visually impaired were likely to feel insecure when in the midst of their sighted colleagues.

Table 5: Feeling Secured in the Midst of Sighted Colleagues accross Respondents' Gender

\begin{tabular}{|c|c|c|c|c|c|c|c|c|c|c|}
\hline \multirow[t]{3}{*}{ Gender } & \multicolumn{8}{|c|}{ Feeling secured in the midst of sighted colleagues } & \multirow{2}{*}{\multicolumn{2}{|c|}{ Total }} \\
\hline & \multicolumn{2}{|c|}{ Strongly agree } & \multicolumn{2}{|c|}{ Agree } & \multicolumn{2}{|c|}{ Disagree } & \multicolumn{2}{|c|}{ Strongly disagree } & & \\
\hline & No. & $\%$ & No. & $\%$ & No. & $\%$ & No. & $\%$ & No. & $\%$ \\
\hline Male & 11 & 16.4 & 12 & 17.9 & 27 & 40.0 & 17 & 25.4 & 67 & 100 \\
\hline Female & 1 & 5.0 & 5 & 25.0 & 10 & 50.0 & 4 & 20.0 & 20 & 100 \\
\hline Total & 12 & 13.8 & 17 & 19.5 & 37 & 42.5 & 21 & 24.1 & 87 & 100 \\
\hline
\end{tabular}

Source: Survey data, 2012

\section{Social Activities}

This section focused on the social challenges respondents encounter in their involvement in social activities. As part of exploring the challenges associated with participating in social activities by the visually impaired, a binary logistic regression analysis was done to determine if respondents' involvement in social activities can be predicted from their demographics; age, gender, academic level and age of onset of impairment. However, univariate analysis showed that majority $(66.7 \%)$ were not fully involved in the schools' social activities. This 
could be linked to the level of marginalization the visually impaired experience from their sighted colleagues. About half (50.6\%) showed to be marginalised by their sighted colleagues.

In determining the involvement of respondents in social activities, the outcome variable was involvement, while age, gender, age of onset of impairment, academic level, were used to predict the level of involvement in social activities. The result of the logistic regression presents aNagelkerke'sR ${ }^{2}$ as 0.77 . This implied that about 77 percent of the variation in the dependent variable had been explained by the variation in the independent variables. Thus respondents' age of onset of impairment and academic level had been good predictors of respondents' involvement in social activities. However, it was noted that the age of onset of impairment had the highest contribution $\left(\chi^{2}=6.792, p=0.009\right)$ to respondents involvement in social activities. This was followed by their academic level $\left(\chi^{2}=4.509, p=0.034\right)$. Respondents' gender and age had no statistical significant contribution to their involvement in social activities on campus. This result implied that respondents' involvement in social activities was independent on their gender and age and that the age of onset of impairment and academic level significantly form the basis of their involvement in social activities in the Universities.

Further analysis showed that the EXP (B) value associated with "age of onset" was 8.294 and that associated with academic level was 1.586 . Hence when respondents' level is increased by a unit, the odd ration is 2 times as large and hence respondents are 2 times more likely to participate in social activities. This could be explained by the fact that, the more respondents spend time on campus, the more they become familiar with the environment, hence their willingness to participate in social activities and better attitudes displayed by sighted colleagues. The study, however, expected that as respondents climb higher in their levels, the less their participation in social activities since academic work is assumed to be intensive.

\section{Social Challenges with Academics}

The social challenges respondents encountered in their academic activities were explored in this section. This included getting colleagues to assist them to and from lectures and reading of print text. Respondents were unanimous in their responses. More than half (59.7\%) indicating 52 students did not get colleague to assist them to and from lectures. This implied that despite the delays the conditions of visual impairments cause, less than half $(40.3 \%)$ of their sighted colleagues were still willing to assist them to and from lectures.

It can therefore be deduced that despite the delays the conditions of the visually impaired cause, a greater proportion $(40.3 \%)$ of their sighted colleagues were still willing to assist them to and from lectures. Obtaining help to and from lectures did not differ across respondents' gender. However, differences were observed across respondents' level. Of the 52 respondents who indicated not to obtain help from their sighted colleagues to and from lectures, more than half $(60.4 \%)$ were from levels 400 and 300. This is illustrated in Table 12.

Table 6: I do not easily get Colleagues to assist me to and from Lectures

\begin{tabular}{lll}
\hline Responses & Frequency & Percent \\
\hline Strongly agree & 11 & 12.6 \\
Agree & 41 & 47.2 \\
Disagree & 31 & 35.6 \\
Strongly disagree & 4 & 4.6 \\
\hline Total & $\mathbf{8 7}$ & $\mathbf{1 0 0}$ \\
\hline
\end{tabular}

Source: Survey data, 2012

In Table 13, it is noted that more than half $(68.4 \%)$ of the level 100 respondents agreed that they do not easily get their sighted colleagues to assist them to and from lectures while only 23.8 percent of those in level 400 agreed.

Further assessment showed that although there were differences, the difference observed was marginal $\left(\chi^{2}=\right.$ $14.676, p=0.056$ ). This gives the indication that students in levels 100 and 200 were more likely to obtain help from their sighted colleagues to and from lectures than those in levels 300 and 400.

This should probably be that as students' progress through the levels, either their sighted colleagues do not become so passionate about their conditions anymore or assume that the environment is familiar hence their help is not so much needed. Thus the finding could be linked to Tibebu (cited in Avramidis, Bayliss and Burden (2000) that the degree to which an individual is accepted by his peers and teachers during his or her early years at school is of special importance for it will have a significant consequence on his or her subsequent adjustment. 
Table 7: I do not easily get Colleagues to Assist me to and from Lectures; thus across Respondents Level

\begin{tabular}{|c|c|c|c|c|c|c|c|c|c|c|}
\hline \multirow[t]{3}{*}{ Level } & \multicolumn{8}{|c|}{ Feeling secured in the midst of sighted colleagues } & \multirow{2}{*}{\multicolumn{2}{|c|}{ Total }} \\
\hline & \multicolumn{2}{|c|}{ Strongly agree } & \multicolumn{2}{|c|}{ Agree } & \multicolumn{2}{|c|}{ Disagree } & \multicolumn{2}{|c|}{ Strongly disagree } & & \\
\hline & No. & $\%$ & No. & $\%$ & No. & $\%$ & No. & $\%$ & No. & $\%$ \\
\hline 100 & 2 & 10.5 & 13 & 68.4 & 3 & 42.1 & 1 & 5.3 & 19 & 100 \\
\hline 200 & 2 & 10.5 & 9 & 47.4 & 8 & 42.1 & 0 & 0.0 & 19 & 100 \\
\hline 300 & 1 & 3.6 & 14 & 50.0 & 12 & 42.9 & 1 & 3.6 & 28 & 100 \\
\hline 400 & 6 & 28.6 & 5 & 23.8 & 8 & 38.1 & 2 & 9.5 & 21 & 100 \\
\hline Total & 11 & 12.6 & 41 & 47.1 & 31 & 35.6 & 4 & 4.6 & 87 & 100 \\
\hline
\end{tabular}

Source: Survey data, 2012

Getting colleagues to read print texts for respondents was found to be a major challenge as far as academic works are concerned. About 90.8 percent were of the view that they did not get their colleagues to assist them with the reading of print texts. This result was unsurprising since sighted colleagues also have their print texts to read, hence even if there will be any help, that will come when sighted colleagues feel that they have covered their print texts extensively, which is less likely.

Additionally, analysis on representation of visually impaired in Students Representative Council (SRC) activities was at the lowest. The study assessed if there were any differences in the mean representation of students with visual impairment in SRC activities across the universities. Table 14 shows the results.

Table 8: My Sighted Colleagues do not always Guide me willingly

\begin{tabular}{llllll}
\hline & Sum of squares & df & Mean Square & F & Sig \\
\hline Between Groups & 2.960 & 2 & 1.480 & 1.710 & 0.187 \\
\hline
\end{tabular}

Source; Survey data, 2012

The findings in Table 14 showed that there were no differences in the mean representation of students with visual impairment in SRC activities across the three universities. That is to say opportunities had not been created for students with visual impairment to fully be represented in the SRC activities of the three universities. This could however be that the students with visual impairment themselves did not make the attempt to be part of the SRC.

\section{Transportation Challenges}

Transportation analysis showed that 67.8 percent of the respondents found it difficult to have access to shuttle buses to and from lectures. This is outlined in Table 15.

Table 9: I find it Difficult to Have Access to Shuttle Buses to and from Lectures

\begin{tabular}{lll}
\hline Responses & Frequency & Percent \\
\hline Strongly agree & 28 & 32.2 \\
Agree & 31 & 35.6 \\
Disagree & 14 & 16.1 \\
Strongly disagree & 14 & 16.1 \\
\hline Total & $\mathbf{8 7}$ & $\mathbf{1 0 0}$ \\
\hline
\end{tabular}

Source: Survey data, 2012

This result was unexpected since there are a number of shuttle buses across the three universities for the transportation of students to and from lectures. The results in Table 15 could however be linked to the fact that about 73.5 percent of the results have indicated that drivers on campus do not assist them when boarding their buses.

It is also important to note that further inferential analysis using the chi-square test of independence showed that the challenges of getting access to shuttle bus to and from lectures cut across gender $\left(\chi^{2}=2.240, p=\right.$ 0.056). Over 60 percent of the males who responded to the study attested to this challenge, and 55 percent of females also attested to this.

\section{Accommodation Challenges of Students with Visual Impairment}

This section explored the accommodation related challenges that students with visual impairment encountered on campus. The challenges were explored from how friendly the routes to the halls are for the visually impaired and arrangements in the halls including the safety of the belongings of the students with visual impairment.

As part of exploring the friendly nature of the routes to respondents' halls, the study found out that more than half $(55.1 \%)$ of the respondents described the routes to their halls as life threatening. Of the 87 respondents, $15(17.2 \%)$ strongly agreed that the routes to their halls are life threatening, $33(37.9 \%)$ agreed, 31 (35.6\%) disagreed and $8(9.2 \%)$ strongly disagreed.

Further analysis showed that there were differences $(\mathrm{F}=7.243, \mathrm{p}=0.001)$ in the degree at which the halls are life threatening across the three participating Universities. Table 16 shows the result. 
Table 10: Routes to my Hall are Life Threatening

\begin{tabular}{llllll}
\hline & Sum of squares & df & Mean Square & F & Sig \\
\hline Between Groups & 9.741 & 2 & 4.871 & 7.243 & 0.001 \\
\hline
\end{tabular}

Source; Survey data, 2012

University of Ghana was found to contribute significantly to the difference while no difference was found between University of Cape Cost and University of Education. This result implied that even though the general architecture of Ghana's Public Universities are not disability friendly, much needs to be done at the University of Ghana with regards to how students with visual impairment are accommodated into the halls.

In Table 17, with regards to safety, $56(64.4 \%)$ of the respondents described the arrangements in the halls as unsafe for their mobility. Results on arrangements at the halls for respondents' safety and mobility are presented in Table 17.

Table 11: Arrangements at the Hall do not Ensure Safety in my Mobility

\begin{tabular}{lll}
\hline Response & Frequency & Percent \\
\hline Strongly agree & 14 & 16.1 \\
Agree & 42 & 48.3 \\
Disagree & 25 & 28.7 \\
Strongly disagree & 6 & 6.9 \\
\hline Total & $\mathbf{8 7}$ & $\mathbf{1 0 0}$
\end{tabular}

Source: Survey data, 2012

There was significant differences $(\mathrm{F}=6.673, \mathrm{p}=0.002)$ in the mean. University of Education contributed significantly to the differences $(p=0.001)$. University of Cape Coast did not show any significant $(p=0.006)$ contribution to the differences. This showed that arrangements in the halls of the universities need to be restructured to ensure that the belongings of students with visual impairment are safe. This result was further confirmed as $73(83.9 \%)$ of the respondents showed that they cannot guarantee that their belongings will not be stolen at the halls. Additionally, over 70 percent (72.4\%) of the respondents agreed that the security in the halls was ineffective for their safety. Table 18 shows the results.

Table 12: The Security at the Hall is Ineffective for my Safety

\begin{tabular}{lll}
\hline Response & Frequency & Percent \\
\hline Strongly agree & 28 & 32.2 \\
Agree & 35 & 40.2 \\
Disagree & 16 & 18.4 \\
Strongly disagree & 8 & 9.2 \\
\hline Total & $\mathbf{8 7}$ & $\mathbf{1 0 0}$ \\
\hline
\end{tabular}

Source: Survey data, 2012

This could probably explain the reasons for respondents indicating that they cannot guarantee that their belongings will not be stolen in the halls.

Although some attempts were made to provide separate toilets for respondents, it was found out that about $56(64.3 \%)$ of the respondents have indicated that separate toilets are not provided for their use. The study explored respondents' views on whether sharing a room with a sighted colleague is not always comfortable of which 55.2 percent responded affirmatively. Thus comparatively, the proportion of respondents who responded otherwise was 10.4 percent higher than the proportion of respondents who responded affirmatively.

As part of exploring the effect of accommodation related challenges for students, the study examined if this can affect the academic achievement of the students. Of the 87 respondents, 66.7 percent responded affirmatively, while 33.3 percent responded otherwise. To further explore the level at which accommodation related challenges affect the students, the study performed a chi-square test of independence to determine if respondents' responses were dependent on their gender. The results showed an insignificant $\left(\chi^{2}=0.812, p=\right.$ $0.368)$ relationship between the two variables. This implied that accommodation related challenges affecting the academic achievements of respondents were independent on their gender, and that, both male and female students with visual impairments experience accommodation related challenges which affect their academic achievement. The following reasons dominated among respondents who indicated that accommodation related challenges affect their academic achievement:

1. Unable to make recordings and readings due to loud noise since we use cassettes to learn;

2. Keeping of learning materials become difficult;

3. Libraries in the halls did not have brailed materials; and

4. Roommates do not appreciate our conditions.

The study also examined if there was any mean difference in the accommodation challenges across the three Universities. In this case, the three Universities were used as the factor level. Table 19 shows the results.

In Table 19, it is noted that there existed a significant difference $(F=15.473, p=0.000)$ in the extent to which 
accommodation related challenges affect the academic achievement of the respondents across the universities. This implied that the accommodation related challenges affecting students' academic achievements were different from at least two Universities. Thus the extent to which accommodation related challenges affect students' academic achievements was different across the three Universities.

Table 13: Accommodation Related Challenges Affecting Your Academic Achievement

\begin{tabular}{llllll}
\hline & Sum of squares & df & Mean Square & F & Sig \\
\hline Between Groups & 5.205 & 2 & 2.602 & 15.473 & 0.000 \\
\hline
\end{tabular}

Source; Survey data, 2012

A further post-hoc test was performed to determine which of the Universities contributed most to the mean difference in the challenges associated with accommodation and academic achievement. The post-hoc analysis showed that the University of Ghana had the highest contribution $(p=0.000)$ to the mean difference. The University of Cape Coast and the University of Education had the same level of contribution ( $p=0.504)$. This meant that students with visual impairment at the University of Ghana are most challenged with accommodation issues thereby affecting their academic performance.

This result further means that although the University has made special arrangement for each student with visual impairment to be accommodated in the halls of residence, much need to be done to ensure that accommodation related challenges such as excessive noise making in the halls are brought to the minimal to enhance the studies of students with visual impairment.

\section{Support Services for Students with Visual Impairment in the Universities}

This section identified the support services available to students with visual impairment across the three participating universities. Key variables assessed included orientation and mobility services, medical health services, resource persons, accessibility of the internet, braille machines, Job Access With Speech (JAWS), print machines, digital tape recorders, braille embosser, and braille sheets. Table 20 shows the responses on orientation and mobility services.

Table 14: Availability of Orientation and Mobility Services

\begin{tabular}{lll}
\hline Responses & Frequency & Percent \\
\hline Available & 24 & 27.6 \\
Not available & 28 & 32.2 \\
Available but not in sufficient quality & 35 & 40.2 \\
\hline Total & $\mathbf{8 7}$ & $\mathbf{1 0 0}$ \\
\hline
\end{tabular}

Source: Survey data, 2012

In Table 20, it is noted that 67.8 percent of the respondents indicated that there were orientation and mobility services, while 32.2 percent indicated otherwise. Further assessment showed that, $35(40.2 \%)$ of the respondents also showed that although orientation and mobility services were available, these were not in sufficient quantity. This implied that to enable students to enter any environment familiar or unfamiliar and to function safely, effectively, gracefully and independently, there is the need for more available orientation services and mobility services for students as noted by Hill and Ponder (1980).

The study also examined if there were mean differences in the availability of orientation services across the three participating universities. Table 21 shows the results.

Table 15: Availability of Orientation and Mobility Services

\begin{tabular}{llllll}
\hline & Sum of squares & df & Mean Square & F & Sig \\
\hline Between Groups & 18.528 & 2 & 9.264 & 19.299 & 0.000 \\
\hline Source; Survey data, 2012 & & & &
\end{tabular}

In Table 21, it is noted that there was significant difference $(F=19.299, p=0.000)$ in the availability of orientation services for visual impairment across the three participating schools. Further assessment using the Least Significant Difference showed that the University of Cape Coast had the most available orientation support services for visual impairments.

The availability of counselling services was also examined of which the results are shown in Table 22. With regards to the availability of counselling services, 74.7 percent of the respondents indicated that counselling services were available. Of this percentage, 32.2 percent showed that although counselling services were available, these were not in sufficient quantities. 
Table 16: Availability of Counselling Services

\begin{tabular}{lll}
\hline Responses & Frequency & Percent \\
\hline Available & 37 & 42.5 \\
Not available & 22 & 25.3 \\
Available but not in sufficient quality & 28 & 32.2 \\
\hline Total & $\mathbf{8 7}$ & $\mathbf{1 0 0}$ \\
\hline
\end{tabular}

Source: Survey data, 2012

On the other hand, 25.3 percent indicated that there were no counselling services. Further assessment was done to determine if the availability of counselling services for respondents was based on their academic levels. Of the 65 respondents who indicated that counselling services were available, 27.7 percent were in level 400 , 300 and 100 respectively, while 20 percent were in level 200. Further inferential analysis showed that the availability of counselling services for respondents was independent $\left(\chi^{2}=9.267, p=0.159\right)$ on their level. This gives the indication that counselling services were available to all students and that level 100, 200, 300 and 400 students with visual impairment have access to counselling services. Additionally, the study found out that there was mean difference $(F=19.984, p=0.000)$ in the availability of counselling services for respondents across the three participating universities. Table 23 shows the results.

Table 17: ANOVA: Counselling Services are Available

\begin{tabular}{llllll}
\hline & Sum of squares & df & Mean Square & F & Sig \\
\hline Between Groups & 18.448 & 2 & 9.224 & 19.984 & 0.000
\end{tabular}

Source; Survey data, 2012

Additional analysis showed that the University of Cape Coast offered more counselling services to students with visual impairment as compared to the University of Education and University of Ghana.

As part of exploring the Service Support System for respondents, the study also examined the availability of Braille Machines. The descriptive statistics obtained showed that of the 87 respondents, 32.2 percent showed that there were adequate Braille Machines while 67.8 percent showed that though there were Braille Machines, these were not in sufficient quantities. It is important to note, however, that none of the respondents mentioned that there were no Braille Machines. The study also found out that the mean number of Braille Machines differed across the three universities significantly $(\mathrm{F}=23.854, \mathrm{p}=0.000)$. Table 24 shows the ANOVA results.

Table 18: Braille Machines

\begin{tabular}{llllll}
\hline & Sum of squares & df & Mean Square & F & Sig \\
\hline Between Groups & 27.513 & 2 & 13.756 & 23.854 & 0.000 \\
\hline
\end{tabular}

Source; Survey data, 2012

Further post-hoc analysis showed that although Braille Machines were not in sufficient qualities across the three universities, the University of Cape Coast had the highest mean number of Braille Machines.

About 83.9 percent of the respondents showed that there were medical services available for the visually impaired. This implied that majority of the visually impaired received medical support services on campus. Differences were also noted in the mean availability of medical services across the three universities. In other words, there were significant $(\mathrm{F}=16.219, \mathrm{p}=0.000)$ differences in the mean number of medical services across the three universities. Table 25 shows this result.

Table 19: Medical Services

\begin{tabular}{llllll}
\hline & Sum of squares & df & Mean Square & F & Sig \\
\hline Between Groups & 14.954 & 2 & 7.477 & 16.219 & 0.000 \\
\hline
\end{tabular}

Source; Survey data, 2012

The University of Ghana, however, offered more medical service support to students with visual impairment. This result could be supported by the fact that the University of Ghana has two health facilities, one for the students and the other for both the students and the general public. Respondents from the University of Cape Coast however, also reported that they have a Clinic for the students exclusively.

With the availability of Braille Embosser, although only 2.3 percent of the respondents showed that these were unavailable, 79.3 percent showed that these were available but not in sufficient quantities. The mean availability of Braille Embosser also differed across the universities. Table 26 shows the result.

Table 20: Braille Embosser

\begin{tabular}{llllll}
\hline & Sum of squares & df & Mean Square & F & Sig \\
\hline Between Groups & 6.696 & 2 & 3.348 & 6.112 & 0.003 \\
\hline
\end{tabular}

Source; Survey data, 2012

In Table 26, it is noted that there was a significant difference $(F=6.112, p=0.003)$ in the mean number of Braille Embosser across the three universities.

The University of Education was noted having the highest number of Braille Embosser, followed by the University of Cape Coast, while the University of Ghana contributed less to the Availability of Braille Embosser. 
With regards to JAWS, 93.1 percent indicated that JAWS was available. Although more than half of the respondents indicated that there were Resource Persons, it was also noted that about 41.4 percent mentioned that these were inadequate. Table 27 shows the results on the availability of resource persons.

This implied that although there were Resources Persons across the three Universities, these were insufficient. There was, however, no significant difference $(F=5.697, p=0.115)$ in the mean number of Resource Persons across the three Universities. It was also noted that 41.4 percent of the respondents indicated that print magnifiers were unavailable.

\section{Implication and Recommendation}

The study showed that students with visual impairment in Ghana's public universities experience several attitudinal challenges from people in the University community including teachers, resources persons, fellow students and even drivers which affect their academic achievement. Many students with visual impairment did not always get their sighted colleagues to guide them willingly on campus. Additionally, the study highlighted that routes to the halls across the universities had not been disability friendly making them life threatening for the students with visual impairment, and that arrangements in the halls as well as security were unsafe for the mobility of the visually impaired and also making it difficult to guarantee the safety of their belongings.

The study concluded that students with visual impairments in Ghana's public universities are constantly challenged by classroom instructional strategies, delays in getting instructional materials among other relevant facilities. Advancements in modern technology have made learning much more accessible. Students with visual impairment can utilise enlarged print or synthesized voice adaptations on the computer. Although machines were available to enlarge the print of any printed material, to convert printed material to braille, or convert printed material into a synthesized voice, these were found to be solely inadequate to enhance quality learning among students with visual impairment in Ghana's public universities.

In response to the findings and conclusions arising from the study, the following recommendations are made for policy making:

Orientation and mobility services for students: The purpose of services for the visually impaired is to provide eligible individuals with visual impairments the opportunities and support that will enable them to become independent, active, self-sustaining members of their community. To enable students to be more familiar with the university in order to function safely, effectively, gracefully and independently, there is the need for more orientation and mobility services for students with visual impairments. Thus it is important that resource persons in collaboration with the University Management in Ghana's public universities organize more orientation and mobility services for students with visual impairment. This will provide the opportunity by allowing the visually impaired live as independently as possible in the university environment with a maximum degree of self-direction.

Training of students about inclusive setting: There is the need for the University Management to conduct periodic training sessions for sighted students to improve their understanding of the capabilities and needs of individuals who are visually impaired on campus.

There is also the need for increased access to equipment and materials. There is also often a range of support services required for the student with visual impairment. Adequate arrangements should be made by the Ministry of Education for teaching and the learning of the students with visual impairment at the university level. Such arrangement should focus on ensuring that they have adequate learning materials including (Braille Machines, JAWS, tape recorders and Braille sheets) and stimulating environment for teaching and learning as well as for assessment.

Additionally, there should be adequate provision of communication and technology hardware and software for students. Such facilities should include desktop computers, laptops, updated screen reader software, Braille printers, speech Braille translation software, and Braille printers among other relevant equipment. NonGovernmental Organizations can also be responsible for this as their social commitment towards the education of the disabled.

Very important is the suggestion for the periodic in-service training of lecturers who teach in the universities that are practising inclusive education for students with visual impairment: Inadequate training relating to inclusive education may result in lowered teacher confidence as they plan for inclusive education. Teachers who have not undertaken training regarding the inclusion of students with disabilities, may exhibit negative attitudes toward the inclusion system. The Special Education Division of the Ministry of Education in conjunction with the university authorities including Resource Persons in the various universities should organise training programmes for lecturers to adequately equip them in the handling of students with visual impairment in the inclusive setting to enhance their understanding and improved attitudes regarding inclusion.

\section{REFERENCES}

Agran, M., Alper, S., \& Wehmeyer, M. (2002). Access to the general curriculum for students with significant 
disabilities: What it means to teachers. Education and Training in Mental Retardation and Developmental Disabilities, 37(2), 123-133.

Ainscow, M. (2007). Towards a more inclusive education system: Where next for special Schools. London: Routledge www.ed.gov/about/offices/list/ocr/docs/hq9805.html

Avoke, M. K., \& Avoke, S. K. (2004). Inclusion, rehabilitation and transition services in special education. Winneba: Department of Special Education.

Avramidis, E., Bayliss, P., \& Burden, R. (2000). Inclusion in action: An in- depth case study of an effective secondary school in the South-West of England. International Journal of Inclusive Education, 6, 38-43.

Brandt, (2011). Teachers' attitudes towards Education: Learning from each other. Support for Learning, 19 (3), $137-141$

Creswell, J. W. (2000). Educational research, planning, conducting and evaluating quantitative and qualitative research. Canada: Pearson \& Merril Prentice-Hall

Dyson, A., \& Gallannaugh, F. (2007). National policy and the development of inclusive school practices: a case study. Cambridge Journal of Education, 37(4), 473-488.

Fuller, D. (2004). Inclusive schools movement and the radicalisation of special education reform. Exceptional Children, 60(4), 294-309.

Gadagbui, G. Y. (2006). What does the public say about the "controversial" communication mode(s) for the hearing impaired in Ghana?, African journal of Special Education, 4(2), 275.

Gyimah, E. K. (2006). Teachers' attitudes to inclusion in Ghana. Unpublished Phd thesis, University of Leeds, United Kingdom.

Mensah, K. A. (2000). Ensuring effective inclusion of persons with disabilities in Ghana. The Winneba Educational Bulletin, 1(8), 22-28

Ocloo, M. A. (2000). Perception of basic education school teachers towards inclusive education in the Hohoe District of Ghana. International Journal of Inclusive Education, 12(5), 639 -650

Spowart, J. (2006). Hotel school students' views of their preparation for work integrated learning: An exploratory study. Asia Pacific Journal of Cooperative Education, 7(2), 10-15.

UNESCO (1994). The Salamanca Statement and framework for action on special needs education. Paris: UNESCO

United Nations (2006). Convention on the rights of persons with disabilities and optional protocol. New York: United Nations.

World Education Forum (2000). The Dakar framework for action. Paris: UNESCO

Yin, R. K. (2003). Case study research: Design and methods ( $3^{\text {rd }}$ ed.). London: Sage Publications. 